\title{
Exposure to ionising radiations arising from the operation of nuclear installations and cancer mortality
}

\author{
G. López-Abente $\cdot$ E. Vidal-Ocabo $\cdot$ O. Tello-Anchuela $\cdot$ N. Aragonés $\cdot$ \\ J. García-Pérez • R. Pastor-Barriuso • B. Pérez-Gómez • M. A. Jiménez \\ J. M. Martín-Valdepeñas $\cdot$ M. García-Talavera $\cdot$ L. Ramos $\cdot$ M. Pollán
}

Received: 28 November 2011/Accepted: 23 February 2013/Published online: 16 April 2013

(C) Islamic Azad University (IAU) 2013

\begin{abstract}
World-wide controversy continues to surround the question of whether exposure to ionising radiations arising from nuclear power plants and radioactive fuel cycle facilities could increase the risk of cancer. The objective was to analyse cancer mortality in towns close to Spanish nuclear power plants and radioactive fuel cycle facilities by reference to their history of exposure to artificial radiation generated by such emissions. An ecological cancer mortality study was conducted to know the effect of artificial radiation, estimated taken into account the magnitude of emissions, in towns $\leq 30 \mathrm{~km}$ of any installation. A model of atmospheric and aquatic dispersion of radionuclides was used. As reference, towns within a $50-100 \mathrm{~km}$ radius were matched with exposed by socio-demographic characteristics. For analysis purposes, log-linear Poisson models were fitted. The cumulative effective dose was the measure of exposure. Mortality rates ratios were calculated for each tumour site. Natural radiation and socio-demographic matching variables were included in the models,
\end{abstract}

G. López-Abente $(\bowtie) \cdot$ E. Vidal-Ocabo · O. Tello-Anchuela .

N. Aragonés · J. García-Pérez · R. Pastor-Barriuso ·

B. Pérez-Gómez · M. Pollán

Área de Epidemiología Ambiental y Cáncer, Centro Nacional de Epidemiología, Instituto de Salud Carlos III, Monforte de Lemos

5, 28029 Madrid, Spain

e-mail: glabente@isciii.es

G. López-Abente $\cdot$ E. Vidal-Ocabo · N. Aragonés .

J. García-Pérez · R. Pastor-Barriuso · B. Pérez-Gómez ·

M. Pollán

CIBER Epidemiología y Salud Pública (CIBERESP),

Madrid, Spain

M. A. Jiménez · J. M. Martín-Valdepeñas ·

M. García-Talavera · L. Ramos

Nuclear Safety Council, Justo Dorado, 11, 28040 Madrid, Spain with 'installation' as a random effects term. The estimated cumulative artificial radiation dose was below $350 \mu \mathrm{Sv}$ for all sites. For nuclear power plants overall, analysis showed no positive association with increases in the cumulative dose. In the joint analysis of radioactive fuel cycle facilities, however, mortality was observed to rise with increases in the estimated radiation dose in the case of lung, bone and colorectal cancer, and in breast cancer among women. These results would not appear to be due to exposure arising from the operation of the installations, since were not reproduced around installations of the same type.

Keywords Environmental pollution/prevention and control · Epidemiology · Industrial pollution · Nuclear power - Spatial epidemiology

\section{Introduction}

For some years now, controversy has surrounded the question of whether exposure to ionising radiations stemming from effluent discharges during the operation of nuclear power plants (NPPs) could increase the incidence of cancer in the exposed population.

A number of reports on childhood leukaemias in England (Cook-Mozaffari et al. 1989) and Germany (Michaelis et al. 1992), along with other papers published recently (Hoffmann et al. 2007; Kaatsch et al. 2008) including a meta-analysis (Baker and Hoel 2007), have shown an increase in risk among the population residing near nuclear installations. The authors indicated that, according to current radiobiological theory, this excess risk is not to be expected, in view of the low levels of exposure to artificial radiation proceeding from the installations. Efforts have, since, been made to replicate these results in the UK 
(Bithell et al. 2008), France (Laurier et al. 2008) and, more recently, in a cohort study in Switzerland (Spycher et al. 2011), without statistically significant excess risk being found. In this respect, it is estimated that exposure to radioactive effluents from facilities currently in service is several orders of magnitude below the limit values set by regulatory requirements (in Spain $0.1 \mathrm{mSv} / \mathrm{year}$ at NPPs and $0.3 \mathrm{mSv} / \mathrm{year}$ at all remaining nuclear installations).

Most of the studies cited used 'distance to installation' as the variable of exposure, without using estimates of the dose emanating from the effluent itself. This method of classifying individuals may entail misclassification bias, reducing study's ability to detect possible risks associated with exposure to installations discharges. Despite the fact that efforts have been made to reconstruct the dosimetric history of populations living in the neighbourhood of these types of installations (National Research Council 1995), it is difficult to find epidemiological cancer studies in the literature which include dose estimates incorporating information on the effluents discharged by such installations. In Spain, few studies have been undertaken on population health in the vicinity of NPPs and radioactive fuel cycle facilities (NFFs) (López-Abente et al. 1999, 2001; Silva-Mato et al. 2003) and these also use distance from town of residence to installation as the measure of exposure.

This study aimed to analyse cancer mortality (1975-2003) in towns lying near Spanish NPPs and NFFs and its possible relationship with their history of exposure to artificial radiation generated by discharges arising from the operation of such installations, using other Spanish towns that displayed similar socio-demographic characteristics, but were not situated in the vicinity of these installations as reference for comparison purposes.

\section{Materials and methods}

\section{Study design}

Cancer mortality was studied in towns situated near seven NPPs and five NFFs that had been operational in the period 1975-2003. With the exception of El Cabril and Juzbado, the NFFs are uranium mills usually located in mining areas. El Cabril is a nuclear waste storage facility built on the site of an abandoned uranium mine and Juzbado is a factory of uranium oxide fuel. A map including site and year of start-up of NPPs and NFFs in Spain was provided by López-Abente et al. (2001).

This was an ecological retrospective cohort study, with a population base made up of the inhabitants of towns neighbouring the nuclear installations under review. The area falling within a $30-\mathrm{km}$ radius of any such installation was the 'exposed zone', while selected towns lying within a $50-100-\mathrm{km}$ radius were the 'reference zone'. The area falling within a $30-\mathrm{km}$ radius of these installations is radiologically monitored by the Nuclear Safety Council (NSC). Exposure to artificial radiation in the reference zone was assumed to be nil.

This paper presents the results on mortality due to stomach [International Classification of Diseases-9 (ICD) 151], colorectal (ICD 153-4, 159.0), lung (ICD 162), bone (ICD 170), connective tissue (ICD 171), breast (in women, ICD 174), brain cancer, and to other tumours of the central nervous system (CNS) (ICD 191-192), thyroid (ICD 193), bladder (ICD 188), kidney (ICD 189), ovary cancer (ICD 183), non-Hodgkin lymphomas (NHLs) (ICD 200, 202), myeloma (ICD 203), Hodgkin's disease (ICD 201) and leukaemias (ICD 204-208), in towns situated adjacent to nuclear facilities. The induction period used was 10 years, with the exception of leukaemias which were 1 year (Parkin et al. 1996).

Follow-up covered the period 1st January 1975-31st December 2003 in the case of installations which had come into operation prior to 1 st January 1975, and dated from the respective installations' entry into service in all other cases. For the seven NPPs as a whole, 328 towns within a $30-\mathrm{km}$ radius and 303 within a $50-100-\mathrm{km}$ radius were included in the study, matched by number of inhabitants, percentage of illiteracy, farmers and unemployed, province according to the 1991 census, and income level (Ayuso-Orejana et al. 1993). The reference towns were selected at random from among all those that met the matching criteria. For the five NFFs as a whole, 177 and 174 towns in the exposed and reference zones, respectively, were included in the study, matched as above.

Data were supplied by the National Statistics Institute (INE). Individual mortality records were broken down by cause, sex, age group, year of death and town of residence. The populations breakdown by sex, age and year for towns included, was obtained from the population census (1981, 1991, 2001) and municipal rolls $(1986,1996)$ as furnished by the INE. Relying on a log-linear polynomial regression model, interpolation was used to estimate annual municipal population figures for the period, 1981-1991 (Aickin et al. 1991). Pre-1981 populations were extrapolated by a linear procedure, allocating more weight to the nearest census year. With the annual population estimates for each town, person-years for each age band $(0-4, \ldots, 65-74,75+)$, sex and period (1975-1978, 1979-1983,.., 1999-2003) were then calculated.

Table 1 shows the general characteristics of the subjects included in the study, for each installation. According to the 1991 census, the total population included in the $0-30-\mathrm{km}$ area was 644,064 persons. In the case of NPPs, the study's population base across the follow-up period amounted to a total of 5 million person-years in the $0-30-\mathrm{km}$ belt, and to 
6 million in the reference zone; and in the case of NFFs, the calculations showed 6 and 8 million person-years in the exposure and reference zones, respectively.

\section{Effective dose estimation}

To estimate the effective dose received by the population due to artificial radiation, models applied in international dose calculation standards, as compiled by the International Atomic Energy Agency (IAEA 2001), were used. This estimation was computed by NSC technicians and a detailed report of the procedures has recently been published (Jiménez et al. 2011). Briefly, isotope-specific radioactivity was taken into account, using original data obtained through a historical review of the records kept by NSC and the respective installations from the time they entered into service. A Gaussian model of atmospheric dispersion, with negligible diffusion, total reflection in soil and constant conditions of turbulence in each period of integration was used. The aquatic dispersion model assumed instantaneous, complete mixing of waters downstream from the discharge point, except in the case of seaside sites where dilution of radionuclides was estimated to occur within a 370-m-wide strip along the coast.

Once the radionuclide concentrations in installations' physical environment had been ascertained, the processes whereby such radionuclides reached individuals in the population, whether through direct impact or via the trophic chain was then reproduced. These mechanisms constitute the 'exposure pathways', the properties of which are specific to each site. For effluents released into air, external exposure (both to the plume itself and to the deposits accumulated in the soil), and human-body intake through inhalation and ingestion of contaminated foods, whether vegetable or animal, were considered. Insofar as effluents released to the aquatic environment were concerned, the following were considered: external exposure to sediments on river banks or beaches, ingestion of drinking water and fish and shellfish, and other contaminated foods of vegetable or animal origin, as described above (García-Talavera et al. 2010).

The estimated effective doses for town populations are the best-estimate annual doses received by the average adult person, for each town studied. Using these estimates, a cumulative exposure dose was allocated to each town population age and year stratum, thus obtaining an estimation of the average cumulative dose received by each birth cohort in each exposure period.

Natural radiation dose estimation

To estimate the dose of naturally occurring radiation, the calculations followed the methodology described in García-Talavera et al. 2007. Since natural radiation was assumed to be constant in time, a single value was estimated for each town. The exposure pathways considered were: cosmic radiation, terrestrial gamma radiation, inhalation of radon and thoron, and internal exposure to the remaining natural isotopes through ingestion of water and food. Estimates were expressed as mean values of the effective dose received by the inhabitants of each town and were obtained using the best information available for each of these parameters. The experimental data were drawn from the natural gamma radiation map of Spain (Suárez et al. 2000), previous NSC-sponsored research projects and tailored measurement campaigns. For calculating the dose in the case of radon, a great proportion of the surrounding towns affected were directly sampled (Quindós Poncela et al. 2003, 2004). In the case of variables having a minor contribution and those for which no local data were available (e.g. exposure to thoron or radioactivity in foods), national or world averages, or parameterisations furnished by the UNSCEAR were used. With respect to dose conversion factors, values proposed by the International Commission on Radiological Protection (ICRP) and stipulated in national legislation (RPSRI, 2001) transposing EU Directive 96/29 were used with the exception of factors corresponding to doses arising from external exposure to deposits in soil, in which case other sources had to be used (EPA 2002).

\section{Statistical analysis}

To analyse the association between cancer mortality and exposure to artificial radiation, cumulative doses were categorised into four levels, applying an algorithm designed to maximise heterogeneity among categories, as follows: (1) recorded doses are ranked in ascending order, (2) accumulated person-years per dose are calculated, (3) cut-off points that establish the quartiles of person-years are calculated, (4) a margin of variation is allocated to either side of each cut-off point, the largest dosimetric 'jump' within this range is sought, and this point is then chosen. This margin is calculated in such a way that, at minimum, each category will have a given proportion $(85 \%)$ of the population which is similar to what it would have if the cut-off points were population quartiles.

For analysis purposes, log-linear models were fitted on the assumption that the number of deaths per stratum followed a Poisson distribution. The study's main exposure variable was the effective dose for each year and town. The measure of exposure used was the cumulative effective dose: this involved taking individual age strata and birth cohorts for each town and considering the estimated doses in each year of exposure relevant for the stratum in question. The cumulative effective dose was the main explanatory covariate in the models. The dependent variable was 


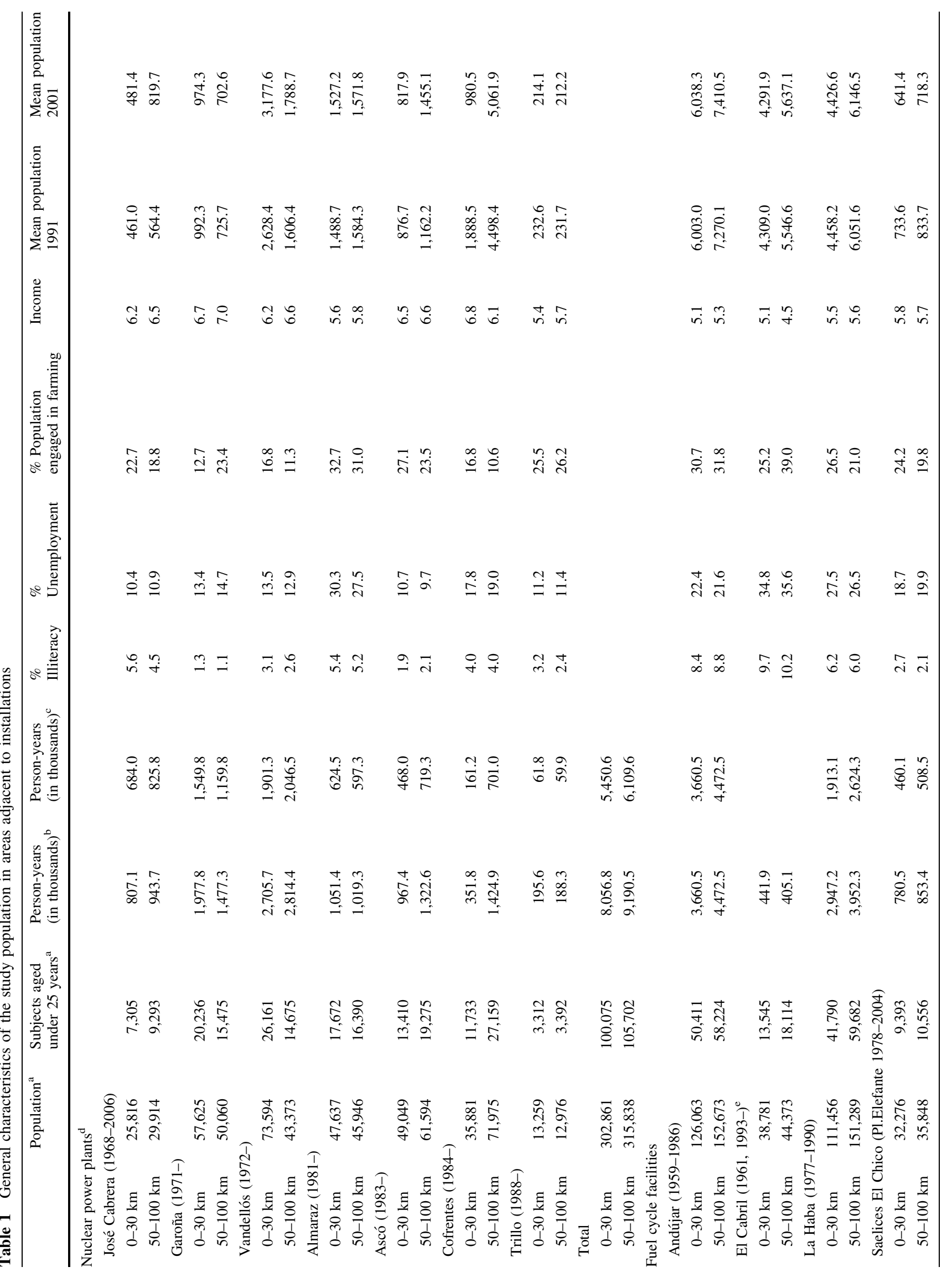




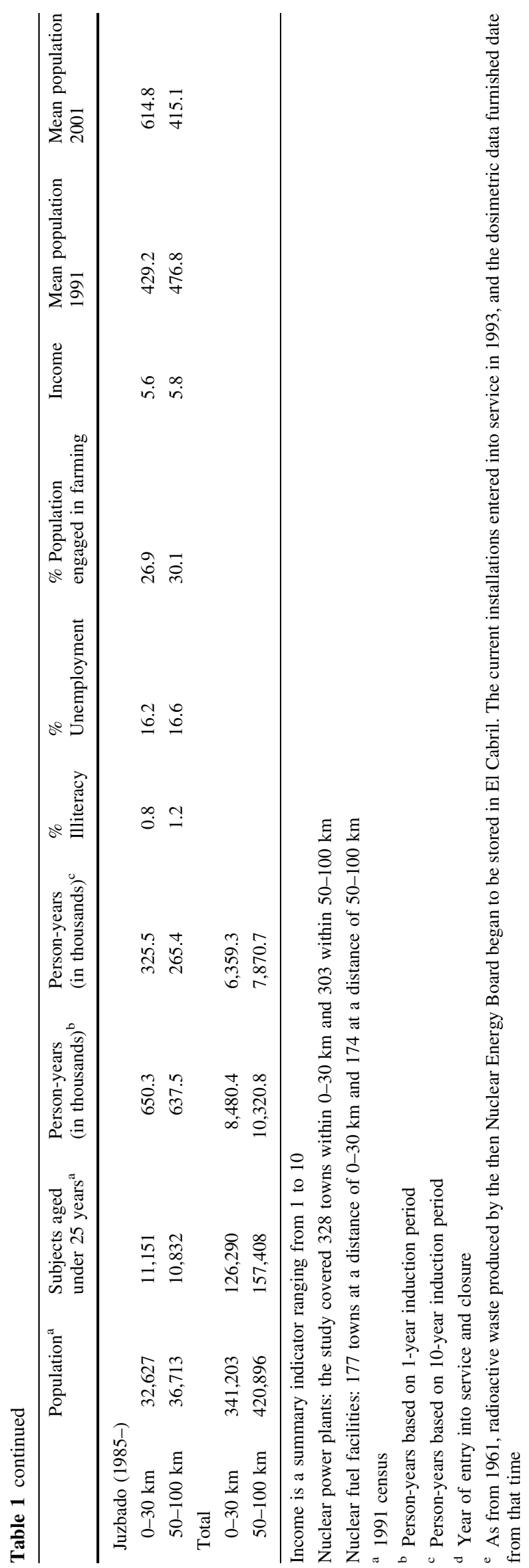

the mortality rate (with person-years included as offset in the models). The regression coefficient of the exposure term gave the logarithm of the mortality rates ratios (RRs) for each malignant tumour.

In these Poisson regression models, the following variables were included as covariates: age group, period, naturally occurring radiation, and socio-demographic matching variables (percentage of illiteracy, farmers and unemployment and income level). In the joint analysis of the installations, the variable 'installation' was included as a random effects term (Gelman and Hill 2007). Moreover, specific analyses on individual installations were run.

Exposure was analysed as a continuous variable, and in another model, as a categorical variable; in the former case, a linear relationship with dose was assumed, and the RR and its confidence interval were estimated for an increase of $10 \mu \mathrm{Sv}$ in the cumulative effective dose; in the latter case, the RR and its confidence interval were estimated for the respective exposure levels, which enabled the 'shape' of the relationship between dose and mortality to be ascertained. The existence of a dose-response gradient is estimated by considering the statistical significance of the inclusion of the exposure variable categorised in the model as a continuous variable. In the second analysis, the median dose in each exposure category was used (Thakur 1985; Thomas 2009). Model results were checked and corrected for overdispersion problems (Breslow 1984) using robust methods (Zellels 2006).

\section{Results and discussion}

Table 2 shows the ranges of exposure estimations due to artificial radiation expressed as cumulative effective dose in microSievert, and to annual natural radiation in towns in these installations' respective vicinities. The magnitude of the estimated levels of artificial radiation, to which populations in the proximity of installations are exposed, is very low. The highest cumulative exposure levels for NPP, $303 \mu \mathrm{Sv}$, were registered in the Garoña area, where annual natural radiation exposure ranges from 1.67 to $2.28 \mathrm{mSv}$ $(2,280 \mu \mathrm{Sv})$. Doses due to the operation of Spanish nuclear facilities represent at most $0.15 \%$ of the total (natural plus artificial) radiation doses which is consistent with the average figure of $0.03 \%$ cited by BEIR V (National Research Council's Committee on Biological Effects of Ionizing Radiations 1990).

Joint analyses of all nuclear power plants and nuclear fuel facilities

Table 3 sets out the results of the joint analysis of the NPPs and NFFs for both sexes, with the different types of cancer- 
Table 2 Range of annual cumulative artificial and natural radiation doses in towns lying in the vicinity of installations

\begin{tabular}{|c|c|c|c|c|}
\hline & $\begin{array}{l}\text { Number of towns } \\
0-30 \mathrm{~km}\end{array}$ & $\begin{array}{l}\text { Cumulative artificial radiation } \\
\text { dose range } \mu \mathrm{Sv}\end{array}$ & $\begin{array}{l}\text { Annual natural radiation dose } \\
\text { range } \mu \text { Sv } 0-30 \mathrm{~km}\end{array}$ & $\begin{array}{l}\text { Annual natural radiation dose } \\
\text { range } \mu \text { Sv } 50-100 \mathrm{~km}\end{array}$ \\
\hline \multicolumn{5}{|c|}{ Nuclear power plants } \\
\hline José Cabrera & 60 & $0.1015-267.5055$ & $2,031-2,837$ & $2,270-4,250$ \\
\hline $\begin{array}{l}\text { Santa } \mathrm{M}^{\mathrm{a}} \text { de } \\
\text { Garoña }\end{array}$ & 68 & $6.5186-303.6069$ & $1,770-2,280$ & $1,760-3,230$ \\
\hline $\begin{array}{l}\text { Vandellós } \\
\text { (I and II) }\end{array}$ & 46 & 0.0711-203.0569 & $1,928-2,627$ & $2,020-2,850$ \\
\hline Almaraz & 33 & $0.0188-27.5820$ & $2,340-5,840$ & $2,360-4,420$ \\
\hline $\begin{array}{l}\text { Ascó } \\
\text { (I and II) }\end{array}$ & 65 & $0.0302-5.6996$ & $1,819-2,786$ & $1,780-2,420$ \\
\hline Cofrentes & 19 & $0.0284-2.6245$ & $1,695-3,730$ & $1,480-2,310$ \\
\hline Trillo & 62 & $0.0458-10.6320$ & $1,752-2,040$ & $2,110-3,620$ \\
\hline Total & $328^{\mathrm{a}}$ & $0.0188-303.6069$ & $1,695-5,840$ & $1,480-4,420$ \\
\hline \multicolumn{5}{|c|}{ Nuclear fuel facilities } \\
\hline Andújar & 22 & $2.9096-348.4730$ & $1,917-2,470$ & $1,480-3,840$ \\
\hline El Cabril & 9 & $0.0004-0.0030$ & $2,705-4,198$ & $1,600-4,170$ \\
\hline La Haba & 26 & $8.1387-138.1390$ & $2,577-20,103$ & $1,830-2,490$ \\
\hline $\begin{array}{l}\text { Saelices El } \\
\text { Chico }\end{array}$ & 44 & $19.8833-289.1230$ & $3,431-15,413$ & $25,70-6,570$ \\
\hline Juzbado & 76 & $0.000015-0.0579$ & $2,416-5,112$ & $1,740-5,400$ \\
\hline Total & 177 & $0.000015-348.4730$ & $1,917-20,103$ & $1,480-5,400$ \\
\hline
\end{tabular}

a Vandellós and Ascó share 25 municipalities located at a distance of less than $30 \mathrm{~km}$ from the two facilities. For this reason, the total number of municipalities included (328) does not correspond to the sum of the municipalities in the vicinity of the nuclear power plants (353)

related mortality shown against the estimated doses of cumulative artificial radiation. For NPPs, no increase in RRs was seen with dose in the analysis using dose categories or in the analysis of dose as a continuous variable, since all the confidence intervals included unity. None of the point estimators for the respective levels of exposure proved to be statistically significant. The table indicates that there was heterogeneity among installations in the case of lung and stomach cancer. All estimates were adjusted for age, period, natural radiation, and socio-demographic variables.

The results for NFFs show mortality increasing with the estimated dose of radiation for lung, bone and colorectal cancer, and for breast cancer in women. Moreover, in the first three cases, analysis of exposure as a continuous variable was also statistically significant. In these tumours, the RRs for all dose categories were $>1$. The heterogeneity test showed that, as between installations, there were differences in risk for breast cancer and lung cancer, though in the latter case these failed to attain statistical significance. When separate analyses were conducted for men and women, the statistical association between dose and mortality in the case of lung cancer was observed among men, while in the case of bone cancer, colorectal cancer, and leukaemias this association only acquired statistical significance among women.
Results for specific nuclear power plants

For NPPs, in general, the results by installation again failed to display any systematic increase in mortality RRs with dose. There are, however, some results of interest (Table 4).

In the José Cabrera area, no association of statistical significance was detected, though in the case of multiple myeloma, all RRs were above unity and statistically significant excess mortality was observable in the third category (RR 3.260; $95 \%$ CI 1.115-9.535). No clear doseresponse relationship was in evidence. The area surrounding the José Cabrera facility registered higher multiple myeloma mortality in both sexes, a result already reported (López-Abente et al. 1999). Yet, this result would not seem to be associated with the dose of artificial radiation, since the RR in the highest exposure category was lower than that observed for the lowest exposure category. Though the aetiology of multiple myeloma is poorly understood, ionising radiation is still considered a possible risk factor for this cancer. The results, however, do not seem to support a causal relationship.

The Garoña area did not register statistically significant excess cancer mortality with increasing dose, with the sole exception of kidney cancer, when dose was analysed as a continuous variable (RR 1.045; $95 \% \mathrm{CI}$ 1.003-1.088). When exposure categories were examined, however, the 
RRs were not coherent with a possible increase in risk with cumulative dose, since the RRs corresponding to the first three levels of exposure were $<1$. In the analysis by sex, a positive relationship was seen only for women. Renal tissue, though apparently not overly radiosensitive (IARC 2000), is the target organ for the toxic effects of uranium (Taylor and Taylor 1997). Nevertheless, this result was not replicated at other NPPs and NFFs. Leukaemia-related mortality was higher among exposed groups, but the RRs displayed no clear upward trend with dose of artificial radiation.

The results around the Vandellós facility showed a dose-response relationship for lung cancer mortality when exposure was analysed as a continuous variable. Even so, neither the joint analysis nor the analysis by sex depicted any clear increase in RRs by category.

In the Almaraz area, the single most notable finding was arguably that for mortality due to connective tissue tumours because, while only one death was registered in the reference zone, ten were recorded in towns lying at distances of less than $30 \mathrm{~km}$. Although this difference gave rise to very high point estimators by the exposure category, their accuracy was very low, due to the small number of deaths. Ovarian cancer displayed excess risk in the highest exposure interval as well as a statistically significant doseresponse relationship.

Other tumours with a positive result were NHLs in the proximity of the Ascó NPP, around which these tumours registered an excess mortality of over $15 \%$ vis-à-vis the reference zone for all exposure categories, in men and women alike, though the dose-response test for trend failed to reach statistical significance.

Finally, in the Cofrentes and Trillo areas, there was no result warranting detailed comment.

As noted above, there is still a controversy as to whether exposure to ionising radiations arising from effluent discharges during routine NPP operation could increase the risk of incidence of cancer in the exposed population. Most of the studies mentioned in "Introduction" were conducted using distance to installation as the exposure variable, with it proving difficult to locate the papers that used an approach similar to the applied here.

The examples of dose reconstruction described in the National Research Council's monograph are radically different to this case, since they involve nuclear weapons test sites and reactor accidents (National Research Council 1995). In 2006, however, a paper was published on leukaemia incidence in subjects under 15 years of age residing in the vicinity of 23 nuclear installations in France (Evrard et al. 2006). The exposure considered was the estimated dose received by the red bone marrow arising from emissions to air. Exposure was assessed by the Institute for Radiation Protection and Nuclear Safety using emission and climatological data and a mathematical model of radionuclide transfer to the environment. The estimated doses ranged from 0.06 to $1.33 \mu \mathrm{Sv} / y e a r$, with an average of $0.17 \mu \mathrm{Sv} /$ year. Standardised incidence ratios were used as the effect measure, and doses categorised into five levels were studied without taking cumulative doses into account. The data corresponded to emissions for the period 1996-2000 and incidence of leukaemias from 1990 to 2001. The designated study area was $40 \mathrm{~km}^{2}$ around each installation, corresponding to a radius of $3.6 \mathrm{~km}$. The paper concludes by stating that no excess or dose-response trend was found in leukaemia incidence among teenagers and young adults, associated with the dose of artificial radiation in the proximity of the 23 French nuclear installations studied.

This study adds no new information about a possible excess of childhood leukaemias in the vicinity of installations, due to the non-existence of cancer incidence records in most of the areas studied and to the fact that mortality data are insufficient to study these types of tumours. Childhood leukaemia mortality in Spain began to decline in the late 1970s as result of therapeutic improvements introduced in this decade (Pollán et al. 1995). Among childhood tumours, leukaemias display the best survival, i.e. from 1980 to 1985 , survival stood at $54 \%$, and by the 1990s haematological tumour survival exceeded $70 \%$ (Peris-Bonet et al. 2010). The same can be said of some of the other above-mentioned tumours having high survival rates, such as Hodgkin's lymphomas, testicular cancer and breast cancer.

Results for specific nuclear fuel facilities

The results of the joint analysis of the NFFs showing a dose-response pattern for lung, bone and colorectal cancer mortality in both sexes and for breast cancer in females, appeared to be determined by the results obtained around the Andújar Uranium Plant (Table 5). This installation accounts for $43 \%$ of the total person-years for NFFs. In the environs of this plant, excess mortality was observed for lung cancer, bone cancer, colorectal cancer and female breast cancer. Lung cancer mortality RRs for men were significantly higher at all levels of exposure than in the reference zone, and above 1.25 for all exposure categories of cumulative artificial radiation dose, with a statistically significant trend. In Andújar, an earlier cohort study highlighted higher lung cancer mortality associated with occupational exposure to radiations among Nuclear Energy Board employees engaged in uranium processing (Rodríguez Artalejo et al. 1997). In this study, lung cancer mortality rates in men and women were higher than those in the reference zones, with a significant dose-response association in men, yet the nature of the study meant that the most important confounding factor for this tumour, 


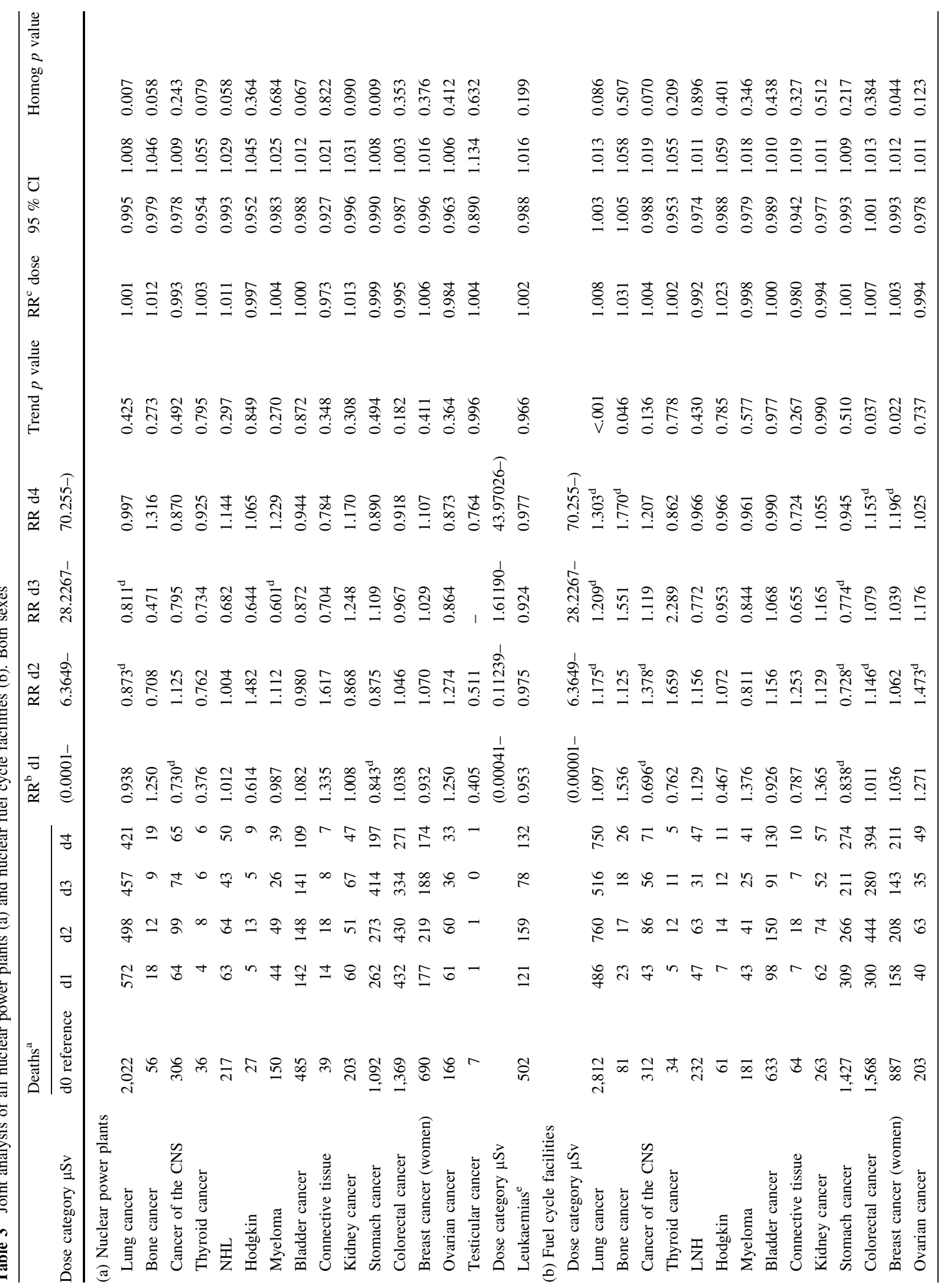




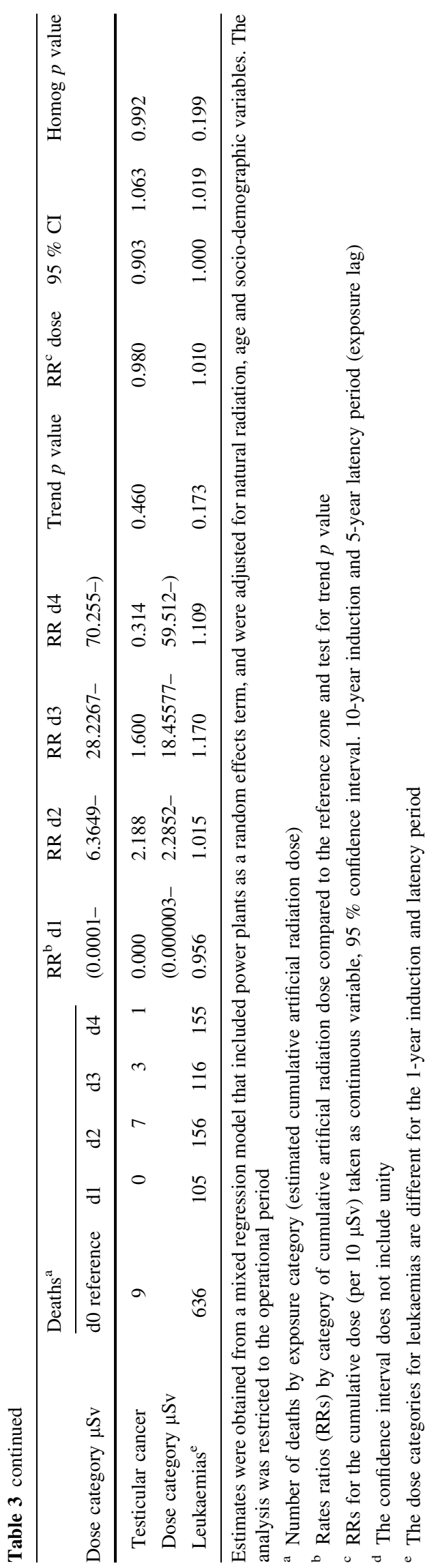

namely, tobacco use, could not be controlled for. Excess mortality was also observed for colorectal cancer in both sexes, and for breast cancer and leukaemias among women.

Of the remaining NFF, the only one warranting special mention is Saelices El Chico, where higher central nervous system (CNS) cancer mortality rates were observed in the highest exposure categories. Thus, of the 24 deaths registered in the $0-30-\mathrm{km}$ zone, 11 occurred in the highest exposure category, with this pattern being applicable to men and women alike. Ionising radiation can induce tumours of the CNS, though the relationship is not as strong as for several other tumours (UNSCEAR 2008).

The nuclear fuel cycle generates discharges of artificial radionuclides, and isotopes of plutonium, americium, cesium, strontium, iodine, polonium, uranium and thorium in particular. In some countries, this has led to the study of radio-analytical data on autopsy, foetal, urine and dental material in the general population (Hodgson et al. 2004; Mangano et al. 2003). These studies show that all such discharges leave biological traces in exposed populations, which can be detected through isotopes that are not present in nature. For radioactive elements with a very long half life, chemical toxicity far outweighs radiological toxicity (e.g. rubidium versus natural uranium). Uranium's chemical toxicity is more important than its radiological toxicity and has led the French authorities to regulate the limits of ingestion and inhalation of uranium compounds to 150 and $2.5 \mathrm{mg}$, respectively, without considering the isotopic composition of the element (CEA 2003).

In epidemiological terms, the problem of the chemical toxicity of these artificial elements is very little studied in human populations and might be an avenue to be considered in the explanation of phenomena that do not fit into current radiobiological knowledge (Hodgson et al. 2004).

One aspect to be borne in mind when assessing the results is the presence of other types of polluting industries in the vicinity of nuclear installations. There are $11 \mathrm{pol}-$ luting industries located near the Andújar Uranium Plant, namely, eight ceramic manufacture plants, two waste storage sites and a paper mill. The ceramic industry is characterised by its heavy discharges of $\mathrm{SO}_{2}$, fluoride and $\mathrm{PM}_{10}$. While these types of discharges could theoretically contribute to the excess lung cancer observed, they would not account for the results obtained for bone cancer and leukaemias. Furthermore, excess lung cancer mortality was not observed among women, something that could point to either an occupationally related effect, or alternatively, to differential lifestyle habits. Excess bone cancer mortality was only observed among women, with an RR of over 1.70 in all the exposure intervals. Some radionuclides (barium, strontium, radium and transuranic elements) are osteotrophic (CEA 2003). 


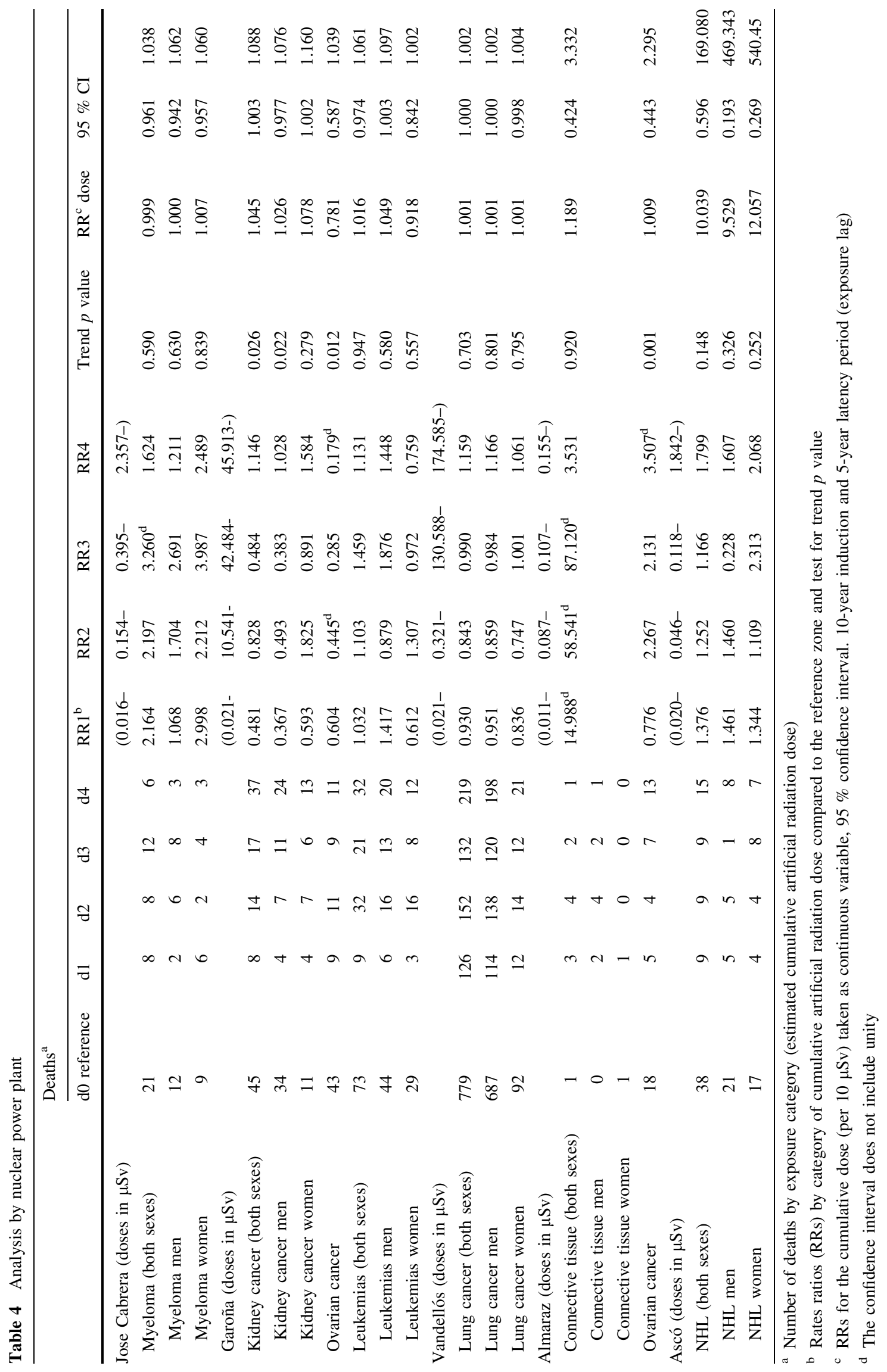


Table 5 Results of the analysis in the area adjacent to the Andújar Uranium Plant

\begin{tabular}{|c|c|c|c|c|c|c|c|c|c|c|c|c|c|}
\hline & \multicolumn{13}{|l|}{ Deaths $^{\mathrm{a}}$} \\
\hline & d0 reference & $\mathrm{d} 1$ & $\mathrm{~d} 2$ & $\mathrm{~d} 3$ & $\mathrm{~d} 4$ & $\mathrm{RR} 1^{\mathrm{b}}$ & $\mathrm{RR} 2$ & RR3 & RR4 & $\begin{array}{l}\text { Trend } \\
p \text { value }\end{array}$ & $\begin{array}{l}\mathrm{RR}^{\mathrm{c}} \\
\text { dose }\end{array}$ & $95 \%$ & $\mathrm{CI}$ \\
\hline Dose category $\mu \mathrm{Sv}$ & & & & & & $(0.036-$ & $7.438-$ & $52.266-$ & $97.282-)$ & & & & \\
\hline Lung cancer (both sexes) & 1,239 & 275 & 295 & 195 & 428 & $1.276^{\mathrm{d}}$ & $1.248^{\mathrm{d}}$ & $1.299^{\mathrm{d}}$ & $1.255^{\mathrm{d}}$ & 0.040 & 1.004 & 0.997 & 1.012 \\
\hline Lung cancer men & 1,111 & 245 & 277 & 176 & 393 & $1.307^{\mathrm{d}}$ & $1.280^{\mathrm{d}}$ & $1.341^{\mathrm{d}}$ & $1.253^{\mathrm{d}}$ & 0.038 & 1.003 & 0.996 & 1.011 \\
\hline Lung cancer women & 128 & 30 & 18 & 19 & 35 & 1.103 & 0.876 & 1.083 & 1.332 & 0.310 & 1.020 & 1.001 & 1.039 \\
\hline Bone cancer & 53 & 16 & 11 & 12 & 14 & 1.290 & 1.414 & 1.198 & 1.459 & 0.450 & 1.031 & 0.998 & 1.065 \\
\hline Bone cancer men & 40 & 9 & 7 & 8 & 7 & 0.884 & 1.212 & 1.049 & 0.980 & 0.957 & 1.007 & 0.966 & 1.050 \\
\hline Bone cancer women & 13 & 7 & 4 & 4 & 7 & $2.754^{\mathrm{d}}$ & 2.063 & 1.721 & 2.973 & 0.216 & 1.062 & 1.014 & 1.112 \\
\hline Breast cancer women & 393 & 84 & 76 & 62 & 117 & 1.149 & 1.114 & 1.271 & $1.376^{\mathrm{d}}$ & 0.018 & 1.003 & 0.993 & 1.013 \\
\hline Stomach cancer & 710 & 163 & 92 & 121 & 135 & 0.907 & 0.854 & 1.035 & 1.073 & 0.354 & 1.010 & 1.001 & 1.018 \\
\hline Stomach cancer men & 434 & 100 & 59 & 80 & 85 & 0.881 & 0.860 & 1.192 & 1.054 & 0.258 & 1.011 & 1.001 & 1.021 \\
\hline Stomach cancer women & 276 & 63 & 33 & 41 & 50 & 0.949 & 0.840 & 0.823 & 1.119 & 0.889 & 1.008 & 0.991 & 1.025 \\
\hline Colorectal cancer & 701 & 144 & 165 & 101 & 222 & 1.078 & $1.237^{\mathrm{d}}$ & $1.398^{\mathrm{d}}$ & 1.199 & 0.030 & 1.008 & 1.001 & 1.015 \\
\hline Colorectal cancer men & 363 & 75 & 88 & 49 & 117 & 1.126 & 1.219 & 1.416 & 1.126 & 0.273 & 1.006 & 0.996 & 1.016 \\
\hline Colorectal cancer women & 338 & 69 & 77 & 52 & 105 & 1.027 & 1.253 & 1.388 & 1.294 & 0.039 & 1.011 & 1.001 & 1.021 \\
\hline Dose category $\mu \mathrm{Sv}$ & & & & & & $(0.015-$ & $1.247-$ & $26.775-$ & 70.885-) & & & & \\
\hline Leukaemias & 244 & 52 & 58 & 63 & 62 & 1.248 & 1.300 & 1.122 & 1.490 & 0.141 & 1.010 & 0.995 & 1.026 \\
\hline Leukaemias men & 131 & 24 & 37 & 30 & 37 & 0.968 & 1.457 & 0.986 & 1.584 & 0.274 & 1.013 & 0.992 & 1.034 \\
\hline Leukaemias women & 113 & 28 & 21 & 33 & 25 & 1.643 & 1.104 & 1.286 & 1.401 & 0.272 & 1.007 & 0.988 & 1.030 \\
\hline
\end{tabular}

${ }^{a}$ Number of deaths by exposure category (estimated cumulative artificial radiation dose)

${ }^{\mathrm{b}}$ Rates ratios (RRs) by category of cumulative artificial radiation dose compared to the reference zone and test for trend $p$ value

${ }^{c}$ RRs for the cumulative dose (per $10 \mu \mathrm{Sv}$ ) taken as continuous variable, $95 \%$ confidence interval

d The confidence interval does not include unity

\section{Radiosensitivity of different tissues}

When it comes to interpreting the results, it is advisable to bear in mind that the radiosensitivity of human tissue to induction of cancer is variable (UNSCEAR 2000, 2008). The types of cancer that tend to be more consistently associated with exposure to ionising radiations are leukaemias, cancer involving breast tissue, and thyroid cancer among teenagers and young adults. Although comparatively less susceptible, it also accepted that tumours of the salivary glands, oesophagus, stomach, colon, liver, lung and CNS are associated with exposure to ionising radiations. Those malignancies which have never shown or only sporadically shown an association with this exposure are chronic lymphatic leukaemia, pancreatic cancer, Hodgkin's lymphoma, and tumours of prostate, testicle and cervix (UNSCEAR 2000, 2008). Sites of all the above categories were included in this study. Even so, the statistical associations found were not observed for the most radiosensitive tumours. When it comes to assessing this lack of association, it should be borne in mind that some of the tumours which affect especially radiosensitive organs register high survival rates, as is the case of breast cancer (81\% at 5 years) and thyroid cancer (87\%) (Sant et al. 2009).
Strengths and limitations of the study

One limitation of this study is its use of mortality rather than incidence data. Currently there is not a national cancer incidence registry in Spain, which would allow for this type of approach using incidence data. With the exception of Tarragona, none of the regions included have a populationbased cancer registry. However, the validity of death-certificate diagnoses for investigating cancer in Spain (PérezGómez et al. 2006) and in other western countries is generally accepted (Laplanche 1998; Reynolds et al. 1991).

The study is ecological in the sense that the main exposure variables refer to population groups. Although the matching used to select reference towns was intended to ensure that these would be as similar as possible, to reduce possible confounding effects, the study took no account of the possible influence of other individual exposures of the populations compared (local occupational or environmental exposures). The way of controlling for possible confounding factors is closely limited by the availability of information. The most evident example is tobacco use. The results yielded by women for smoking-related tumours are of special interest, since the prevalence of female smokers in generations 

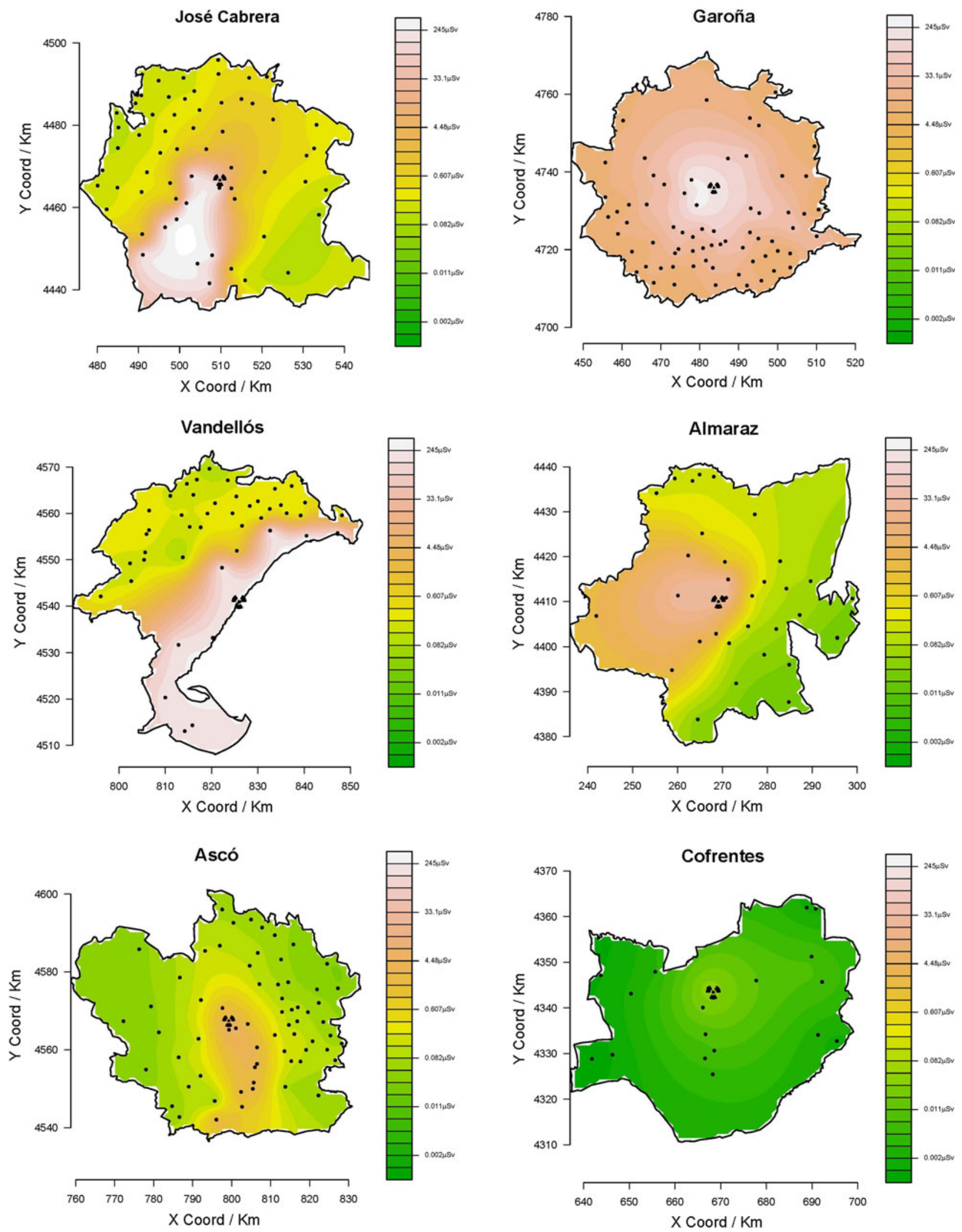

Fig. 1 Distribution of cumulative effective doses arising from effluents discharged by nuclear power plants, depicted on a single scale. Only the towns in the $30-\mathrm{km}$ areas are mapped. Isodose lines were estimated using kriging 
born before 1940 was very low in Spain (López-Abente et al. 1995). With respect to other confounding factors, one strength of this study is the inclusion of the estimated dose of natural radiation in each town. Other sources of exposure to ionising radiations (such as medical or occupational exposures) could not be taken into account. Nonetheless, there is no reason to believe that in this exposure there are differential values which might be associated with artificial radiation.

The effective dose was selected as exposure indicator, since this parameter provides clear benefits in the case of wide-ranging, broad-spectrum studies. This approach has been endorsed by the ICRP in response to a query from the NSC. To estimate effective doses, conservative values were used when best estimates of site-specific parameters were unavailable. While the magnitude of effective doses due to effluents ranged from $3.05 \mathrm{e} 7 \mu \mathrm{Sv}$ to $73.4 \mu \mathrm{Sv}$ per year, the magnitude of doses due to natural radiation ranged from 1,670 to $20,100 \mu \mathrm{Sv}$ per year, though this latter value was obtained in a single town. On average, effective dose due to exposure to natural radiation is 300 times higher than that due to exposure from installations' effluent discharges. One limitation is the impossibility of finding ways of validating the estimated doses by means of environmental or biological measurements drawn from the study area. Although radiological surveillance of such installations and their surrounding areas includes these types of measurements, the values recorded are generally below the detection limits.

The spatial distribution of data classified by the dose category differs from the radial pattern produced by the distances used in previous studies, owing to the fact that the specific characteristics of each site and of land and water use in the zone were considered. The dose arising from effluent discharges depends most on the exposure to liquid effluents (if any) and, to a lesser degree, on atmospheric dispersion, which is determined by the local wind patterns, release height and relief of terrain. The distribution of the cumulative dose by town is depicted in Fig. 1 for some of the NPPs. Although distance might be a good approximation in certain installations (e.g. Garona), the spatial distribution of the estimated dose is generally anisotropic. Hence, in the environs of Almaraz, $66 \%$ of the towns classified by distance would change the level if dosimetric categorisation was applied.

\section{Nuclear safety}

The results of this and earlier studies, coupled with the nonexistence of mortality patterns pointing to an excess risk of cancer in the proximity of these installations, lead to the conclusion that population exposure to radiation arising from their emissions from normal operation of the facilities is very low. The real problem that originated this study lies in the existing deep social concern. This study was undertaken between 2006 and 2009, prior to the nuclear accident caused by the tsunami in Japan (11th March 2011), which marked a 'before and after' in the assessment of the sustainability of nuclear energy and its impact on human and natural ecosystems. Nevertheless, in the light of the existing store of knowledge about the carcinogenic nature of exposure to ionising radiations and the experience gained in nuclear energy production world-wide, it is essential (1) to ensure that the existent NPPs and NFFs are safe against natural disasters or caused accidents, and (2) to seek a reasonable and safe solution for the proper management of the waste generated by such installations. From a public health standpoint, these last two matters-rather than emissions from standard, routine operation of facilities-that are the crux of the problem now confronting nuclear energy, and they are important enough to question the sustainability of this form energy production in the long term.

\section{Conclusion}

In conclusion, this study shows that the cumulative doses of artificial radiation, which the population would have received as a consequence of the operation of the installations across the study period, are very small. This study has detected no results that would consistently indicate a systematic increase in mortality due to any type of cancer associated with the dose of artificial radiation incurred.

Acknowledgments This study was funded by a collaboration agreement between the Nuclear Safety Council and the Carlos III Institute of Health (ISCIII: EVI 1101/06). Mortality data were supplied by the Spanish National Statistics Institute according to a specific confidentiality protocol.

Conflict of interest The authors declare they have no actual or potential competing financial interests.

\section{References}

Aickin M, Dunn CN, Flood TJ (1991) Estimation of population denominators for public health studies at the tract, gender, and age-specific level. Am J Public Health 81:918-920

Ayuso-Orejana J, Fernández-Cuesta J, Plaza-Ibeas J (1993) Anuario del mercado español. Banesto, Madrid

Baker PJ, Hoel DG (2007) Meta-analysis of standardized incidence and mortality rates of childhood leukaemia in proximity to nuclear facilities. Eur J Cancer Care (Engl) 16:355-363

Bithell JF, Keegan TJ, Kroll ME, Murphy MF, Vincent TJ (2008) Childhood leukaemia near British nuclear installations: methodological issues and recent results. Radiat Prot Dosimetry 132:191-197

Breslow NE (1984) Extra-Poisson variation in log-linear models. Appl Stat 33:38-44

CEA (2003). Radiological and chemical toxicology. Clefs CEA no48. Commissariat à l'énergie atomique et aux énergies alternatives 
Cook-Mozaffari PJ, Darby SC, Doll R, Forman D, Hermon C, Pike MC, Vincent T (1989) Geographical variation in mortality from leukaemia and other cancers in England and Wales in relation to proximity to nuclear installations, 1969-78. Br J Cancer 59:476-485

EPA (2002) Federal guidance report 13 cancer risk coefficients for environmental exposure to radionuclides: CD supplement. Oak Ridge National Laboratory, US Environmental Protection Agency, Oak Ridge, Washington DC

Evrard AS, Hemon D, Morin A, Laurier D, Tirmarche M, Backe JC, Chartier M, Clavel J (2006) Childhood leukaemia incidence around French nuclear installations using geographic zoning based on gaseous discharge dose estimates. Br J Cancer 94:1342-1347

Garcia-Talavera M, Matarranz JL, Martinez M, Salas R, Ramos L (2007) Natural ionizing radiation exposure of the Spanish population. Radiat Prot Dosimetry 124:353-359

García-Talavera M, Jiménez M, Martín-Valdepeñas J (2010) Estimación de las dosis a la población por la exposición debida al funcionamiento de las instalaciones nucleares y radiactivas del ciclo de combustible, y a la radiación natural. Consejo de Seguridad Nuclear, Madrid

Gelman A, Hill J (2007) Data analysis using regression and multilevel/ hierarchical models. Cambridge University Press, New York

Hodgson SA, Ham GJ, Youngman MJ, Etherington G, Stradling GN (2004) A review of measurements of radionuclides in members of the public in the UK. J Radiol Prot 24:369-389

Hoffmann W, Terschueren C, Richardson DB (2007) Childhood leukemia in the vicinity of the Geesthacht nuclear establishments near Hamburg, Germany. Environ Health Perspect 115:947-952

IAEA (2001) Generic models for use in assessing the impact of discharges of radioactive substances to the environment. International Atomic Energy Agency, Vienna

IARC (2000) Ionizing radiation, part 1: X- and gamma (y)-radiation, and neutrons. IARC monographs on the evaluation of carcinogenic risks to humans., vol 75. International Agency for Rresearch on Cancer, Lyon

Jiménez MA, Martín-Valdepeñas JM, García-Talavera M, MartínMatarranz JL, Salas MR, Serrano JI, Ramos LM (2011) Realistic retrospective dose assessments to members of the public around Spanish nuclear facilities. J Environ Radioact 102:995-1007

Kaatsch P, Spix C, Schulze-Rath R, Schmiedel S, Blettner M (2008) Leukaemia in young children living in the vicinity of German nuclear power plants. Int J Cancer 122:721-726

Laplanche A (1998) Quality of death certificates in cases of cancer death in France. Bull Cancer 85:967-969

Laurier D, Hémon D, Clavel J (2008) Childhood leukaemia incidence below the age of 5 years near French nuclear power plants. J Radiol Prot 28:401-403

López-Abente G, Pollán M, de la Iglesia P, Ruiz M (1995) Characterization of the lung cancer epidemic in the European Union (1970-1990). Cancer Epidemiol Biomarkers Prev 4:813-820

López-Abente G, Aragonés N, Pollán M, Ruiz M, Gandarillas A (1999) Leukemia, lymphomas, and myeloma mortality in the vicinity of nuclear power plants and nuclear fuel facilities in Spain. Cancer Epidemiol Biomarkers Prev 8:925-934

López-Abente G, Aragonés N, Pollán M (2001) Solid-tumor mortality in the vicinity of uranium cycle facilities and nuclear power plants in Spain. Environ Health Perspect 109:721-729

Mangano JJ, Gould JM, Sternglass EJ, Sherman JD, McDonnell W (2003) An unexpected rise in strontium-90 in US deciduous teeth in the 1990s. Sci Total Environ 317:37-51

Michaelis J, Keller B, Haaf G, Kaatsch P (1992) Incidence of childhood malignancies in the vicinity of West German nuclear power plants. Cancer Causes Control 3:255-263

National Research Council (1995) Radiation dose reconstruction for epidemiologic uses. National Academy Press, Washington
National Research Council's Committee on Biological Effects of Ionizing Radiations (1990) Health effects of exposure to low levels of ionizing radiation: BEIR V. National Academic Press, Washington DC

Parkin DM, Clayton D, Black RJ, Masuyer E, Friedl HP, Ivanov E, Sinnaeve J, Tzvetansky CG, Geryk E, Storm HH et al (1996) Childhood leukaemia in Europe after Chernobyl: 5 year followup. Br J Cancer 73:1006-1012

Pérez-Gómez B, Aragonés N, Pollán M, Suárez B, Lope V, Llácer A, López-Abente G (2006) Accuracy of cancer death certificates in Spain: a summary of available information. Gac Sanit 20(Suppl 3):42-51

Peris-Bonet R, Salmerón D, Martínez-Beneito MA, Galceran J, Marcos-Gragera R, Felipe S, González V, de Toledo Sánchez, Codina J (2010) Childhood cancer incidence and survival in Spain. Ann Oncol 21(Suppl 3):iii103-iii110

Pollán M, López-Abente G, Ruiz-Tovar M, Martínez de Aragón MV (1995) Childhood and adolescent cancer in Spain: mortality time trends 1956-1990. Eur J Cancer 31A:1811-1821

Quindós Poncela LS, Fernández Navarro PL, Gómez Arozamena J, Ródenas Palomino C, Sainz C, Martin Matarranz JL, Arteche J (2003) Natural radiation exposure in the vicinity of Spanish nuclear power stations. Health Phys 85:594-598

Quindós Poncela LS, Fernández Navarro PL, Gómez Arozamena J, Ródenas Palomino C, Sainz C, Martin Matarranz JL, Arteche J (2004) Population dose in the vicinity of old Spanish uranium mines. Sci Total Environ 329:283-288

Reynolds DL, Nguyen VC, Clarke EA (1991) Reliability of cancer mortality statistics in Ontario: a comparison of incident and death diagnoses, 1979-1983. Can J Public Health 82:120-126

Rodríguez Artalejo F, Castaño Lara S, de Andrés Manzano B, García Ferruelo M, Iglesias Martín L, Calero JR (1997) Occupational exposure to ionising radiation and mortality among workers of the former Spanish Nuclear Energy Board. Occup Environ Med 54:202-208

RPSRI (2001). Reglamento sobre Protección Sanitaria contra Radiaciones Ionizantes. Real Decreto 783/2001 de 6 de Julio. BOE

Sant M, Allemani C, Santaquilani M, Knijn A, Marchesi F, Capocaccia R (2009) EUROCARE-4. Survival of cancer patients diagnosed in 1995-1999. Results and commentary. Eur J Cancer 45:931-991

Silva-Mato A, Viana D, Fernandez-SanMartin MI, Cobos J, Viana M (2003) Cancer risk around the nuclear power plants of Trillo and Zorita (Spain). Occup Environ Med 60:521-527

Spycher BD, Feller M, Zwahlen M, Röösli M, von der Weid NX, Hengartner H, Egger M, Kuehni CE (2011) Childhood cancer and nuclear power plants in Switzerland: a census-based cohort study. Int J Epidemiol 40:1247-1260

Suárez E, Fernández J, Baeza A, Moro M, García D, Moreno J (2000) Proyecto MARNA. Mapa de Radiación Gamma Natural. Consejo de Seguridad Nuclear, Madrid

Taylor DM, Taylor SK (1997) Environmental uranium and human health. Rev Environ Health 12:147-157

Thakur AK (1985) Test of homogeneity and trend with medians. Environ Mutagen 7:23-30

Thomas D (2009) Statistical methods in environmental epidemiology. Oxford University Press, New York

UNSCEAR (2000) Sources and effects of ionizing radiation. United Nations Scientific Committee on the Effects of Atomic Radiation, New York

UNSCEAR (2008) UNSCEAR 2006 REPORT Vol. I EFFECTS OF IONIZING RADIATION. United Nations, Vienna

Zellels A (2006) Object-oriented computation of sandwich estimators. J Stat Softw 16:1-16 